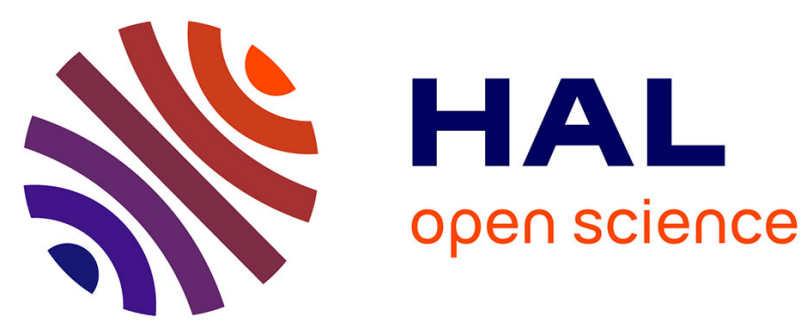

\title{
Supramolecular structure for large strain dissipation and outstanding impact resistance in Polyvinylbutyral
}

Paul Elzière, Paul Fourton, Demassieux Quentin, Alexis Chennevière, Cecile Dalle-Ferrier, Costantino Creton, Matteo Ciccotti, Etienne Barthel

\section{- To cite this version:}

Paul Elzière, Paul Fourton, Demassieux Quentin, Alexis Chennevière, Cecile Dalle-Ferrier, et al.. Supramolecular structure for large strain dissipation and outstanding impact resistance in Polyvinylbutyral. Macromolecules, 2019, 52 (20), pp.7821-7830. 10.1021/acs.macromol.9b01277 . hal-02360676

\section{HAL Id: hal-02360676 https://hal.science/hal-02360676}

Submitted on 13 Nov 2019

HAL is a multi-disciplinary open access archive for the deposit and dissemination of scientific research documents, whether they are published or not. The documents may come from teaching and research institutions in France or abroad, or from public or private research centers.
L'archive ouverte pluridisciplinaire HAL, est destinée au dépôt et à la diffusion de documents scientifiques de niveau recherche, publiés ou non, émanant des établissements d'enseignement et de recherche français ou étrangers, des laboratoires publics ou privés. 


\title{
Supramolecular structure for large strain
}

\section{dissipation and outstanding impact resistance in Polyvinylbutyral}

\author{
Paul Elzière, ${ }^{\dagger, \ddagger}$ Paul Fourton, ${ }^{\dagger, \ddagger}$ Quentin Demassieux, ${ }^{\dagger}$ Alexis Chennevière, \\ Cécile Dalle-Ferrier,,${ }^{\ddagger}$ Costantino Creton ${ }^{\dagger}{ }^{\dagger}$ Matteo Ciccotti, ${ }^{*} \dagger$ and Etienne \\ Barthel $l^{* \dagger}$ \\ $\dagger$ †aboratoire Sciences et Ingénierie de la matière Molle, ESPCI Paris, PSL University, \\ Sorbonne Université, CNRS, F-75005 Paris, France \\ $\ddagger$ Saint-Gobain Recherche, 39 quai Lucien Lefranc, 93300 Aubervilliers, France \\ \Laboratoire Léon Brillouin, CEA Saclay, 91191 Gif-Sur-Yvette, France \\ E-mail: matteo.ciccotti@espci.fr; etienne.barthel@espci.fr
}

\begin{abstract}
For decades, poly(vinylbutyral) (PVB) has been the polymer of choice to improve the impact resistance of laminated glass. PVB presents large rupture strain, large tensile strength and excellent dissipative properties. Here we investigate the relation between macromolecular structure and mechanical properties of plasticised PVB by combining large strain tensile experiments with calorimetry, X-ray and birefringence measurements. We find that the mechanical response is dominated by creep and that this plastic-like flow can effectively be described by a strain dependent viscosity. The commonalities with other toughened polymeric materials are outlined, and especially the role played by phase separated domains with weaker physical bonds. These results could help optimize polymer design for toughness and impact applications.
\end{abstract}




\section{For Table of Contents Use Only}

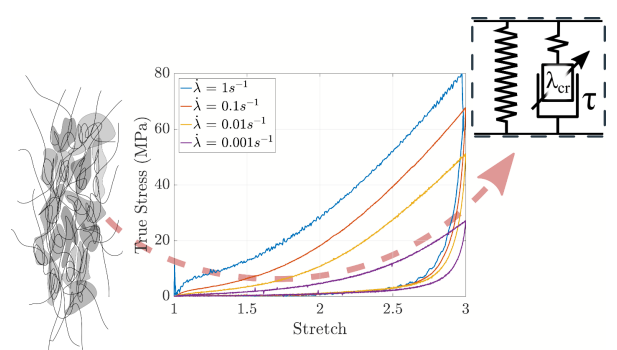

Supramolecular structure for large strain dissipation and outstanding impact resistance in Polyvinylbutyral, by Paul Elzière, Paul Fourton, Quentin Demassieux, Alexis Chennevière,

Cécile Dalle-Ferrier, Costantino Creton, Matteo Ciccotti and Étienne Barthel.

\section{Introduction}

Impact resistant polymers exhibit high deformability, large rupture stress and strong dissipation. Two major questions are: 1) how these properties are related to material structure; 2) how they can be obtained by design through formulation and processing. An interesting example is polyurea, which exhibits a phase separated structure with a soft matrix and nanometric stiff domains resulting from hydrogen bond (H-bond) association. 1 Polyurea shows excellent scratch and impact resistance properties and is used for high performance coatings. Here, we are interested in plasticized poly(vinylbutyral) (PVB), which is commonly used in laminated glass, a safety product used for buildings and vehicles. It comes under the form of an interlayer (typical thickness $0.76 \mathrm{~mm}$ ) sandwiched between two glass plates (ca $2.3 \mathrm{~mm}$ thick each). PVB dramatically enhances the impact performance of this composite. Impacting objects are prevented from breaking their way through the glass while glass splinters are retained once the laminate has shattered.

Because viscoelastic dissipation in the polymer contributes to vibration damping in laminated glass, the small strain rheology of PVB has been thoroughly described in the literature. ${ }^{2 / 7}$ However, if the glass plates fracture under impact, the polymer interlayer undergoes large deformations and the mechanical properties of PVB at large strain play a significant 
role in the energy dissipation process. ${ }^{[89}$ Although it is crucial for our understanding of impact resistance, this large strain regime has received much less attention. Sha et al. ${ }^{10}$ have performed large strain uniaxial tensile tests and used a hyperelastic model to describe the interlayer during impact. However, Hooper et al.11 have shown that such an hyperelastic model is too simple because the response is strongly time dependent. They have also observed a sharp initial stress increase before abrupt softening for strain values ranging from approximately $30 \%$ to $100 \%$, followed by a noticeable strain stiffening above $100 \%$ strains. Seshadri et al ${ }^{12}$ have performed cyclic uniaxial tension tests showing that a large fraction of the energy provided during loading is actually dissipated. Rheological models of PVB ${ }^{13}$ have been developed to capture the coupling between time dependence and non-linearity in a more precise manner. However, most models focus on the loading conditions only while unloading has to be described as well to properly capture the dissipative contributions to adhesion and fracture. 14

Obviously, the outstanding mechanical properties of PVB must be related to the non trivial structure of the macromolecular network. The hydroxyl groups of the vinylalcohol are known to impact the dynamics through hydrogen bonds formed in-between polymer chains. Paul et al $\frac{[15}{\sqrt{15}}$ have found a strong impact of the formation of these supramolecular bonds on the viscosity of PVB solutions. NMR relaxation experiments ${ }^{16}$ have demonstrated the effect of OH-bond association on the molecular scale dynamics of solid PVB. They have also shown that the large amount of plasticiser present in PVB results in a phase separated material consisting of slow $\mathrm{OH}$ rich domains on the one hand and fast plasticizer rich domains on the other hand. However, as observed by Schaefer et al.: "important macroscopic mechanical properties such as stress-strain behavior, creep, aging, and impact strength are poorly predicted from dynamics parameters derived exclusively from NMR experiments". 16

In this paper, our aim is to provide a better understanding of the connection between macromolecular structure and large strain mechanical properties in PVB. Mechanical ex- 
periments, performed as a function of strain rate and temperature, were complemented by birefringence and small and wide angle X-ray scattering (SAXS-WAXS) experiments performed in situ during uniaxial tensile tests. Based on these data, we propose a scenario for the spatial organization of PVB, the connectivity between domains and the dissipation mechanisms occurring at large strain. We show that plastic-like flow is the dominant dissipation mechanism in PVB at large strain, and propose a numerical scheme based on strain dependent viscosity to account for the observed strain hardening.

\section{Materials and methods}

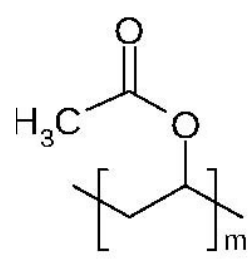

Vinylacetate 1-2 wt $\%$

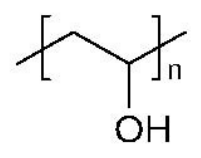

Vinylalcohol 18-20 wt $\%$

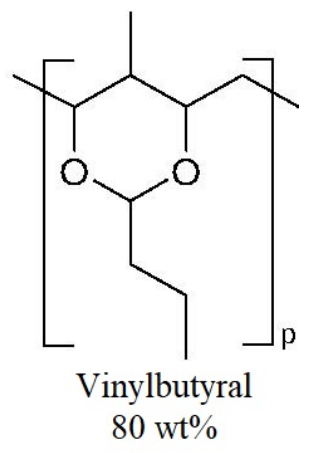

$80 \mathrm{wt} \%$

Figure 1: PVB monomers.

The polymer used in this study is a standard plasticized poly(vynilbutyral) (Solutia RB41). PVB is composed of three monomers (Figure 1) that result from the hydrolysis of vinylacetate into vinylalcohol and from the subsequent reaction of these hydroxyl groups with butyraldehyde to get butyral cycles. In a typical PVB polymer used for laminated glass, only 1-2 wt\% of vinylacetate groups remain after hydrolysis. Usually there are 18$22 \mathrm{wt} \%$ of vinylalcohol monomers and around $80 \mathrm{wt} \%$ of vinylbutyral. PVB grades used for laminated glass also contain up to $30 \mathrm{wt} \%$ triethylene glycol bis(2-ethylhexanoate), a plasticizer which decreases the glass transition temperature from $70^{\circ} \mathrm{C}$ down to $20-30^{\circ} \mathrm{C}$ and increases viscoelastic dissipation under ambient conditions.

The small strain response was measured using dynamic mechanical analysis (DMA - 
TA Instruments Q800). For large strain rheology, cyclic uniaxial tension experiments were conducted on dogbone shaped samples with thickness $h_{0}=0.76 \mathrm{~mm}, 4 \mathrm{~mm}$ width and an active length of $20 \mathrm{~mm}$. At higher stretch rates and lower temperatures, where the material is stiff, the tests were conducted on a Zwick/Roell Hamsler HC25 hydraulic machine with a load cell of $1 \mathrm{kN}$. At lower stretch rates and higher temperatures, where the material is softer, the tests were conducted on a Instron 5565 machine with 10 and $100 \mathrm{~N}$ load cells. Temperature was controlled by a PID thermoregulator 2216L from Eurotherm Automation in a closed cabinet within the range 10 to $70^{\circ} \mathrm{C}$.

Differential scanning calorimetry experiments were conducted on a Q200 apparatus (TAInstruments) in a hermetically closed aluminum pan. Measurements were done under a nitrogen flow of $50 \mathrm{~mm} \cdot \mathrm{min}^{-1}$.

Small and wide angle X-ray scattering experiments were conducted at the Advanced Photon Source (Argonne National Laboratory) 5ID-D, B beamline, on dogbone samples with an effective length of $20 \mathrm{~mm}$. During the scattering experiments, the sample was loaded with a Linkam TST350 device, which is composed of a tensile testing machine enclosed in an oven equipped with a heating element in contact with the sample to control the temperature. The heating element is transparent to X-rays. X-ray scattering was recorded during the application of uniaxial tension with a nominal stretch rate of $0.01 \mathrm{~s}^{-1}$. The stretch was monitored through clamp displacement since no imaging could be made during the test.

Birefringence measurements were conducted on similar samples during uniaxial loading. Two crossed polarizers and two quarter-wave plates are placed around the sample in the usual arrangement. A red filtered $\left(l_{\text {opt }}=650 \mathrm{~nm}\right)$ flat light panel (Effilux BL $200 \mathrm{~mm}$ ) is placed inside the oven of the tensile testing machine. The samples were imaged with a Baumer BM20 industrial camera and a TV lens (Kowa CCTV Lens LZM69M) through the front window of the oven. 


\section{Results}

\section{Small strain response}

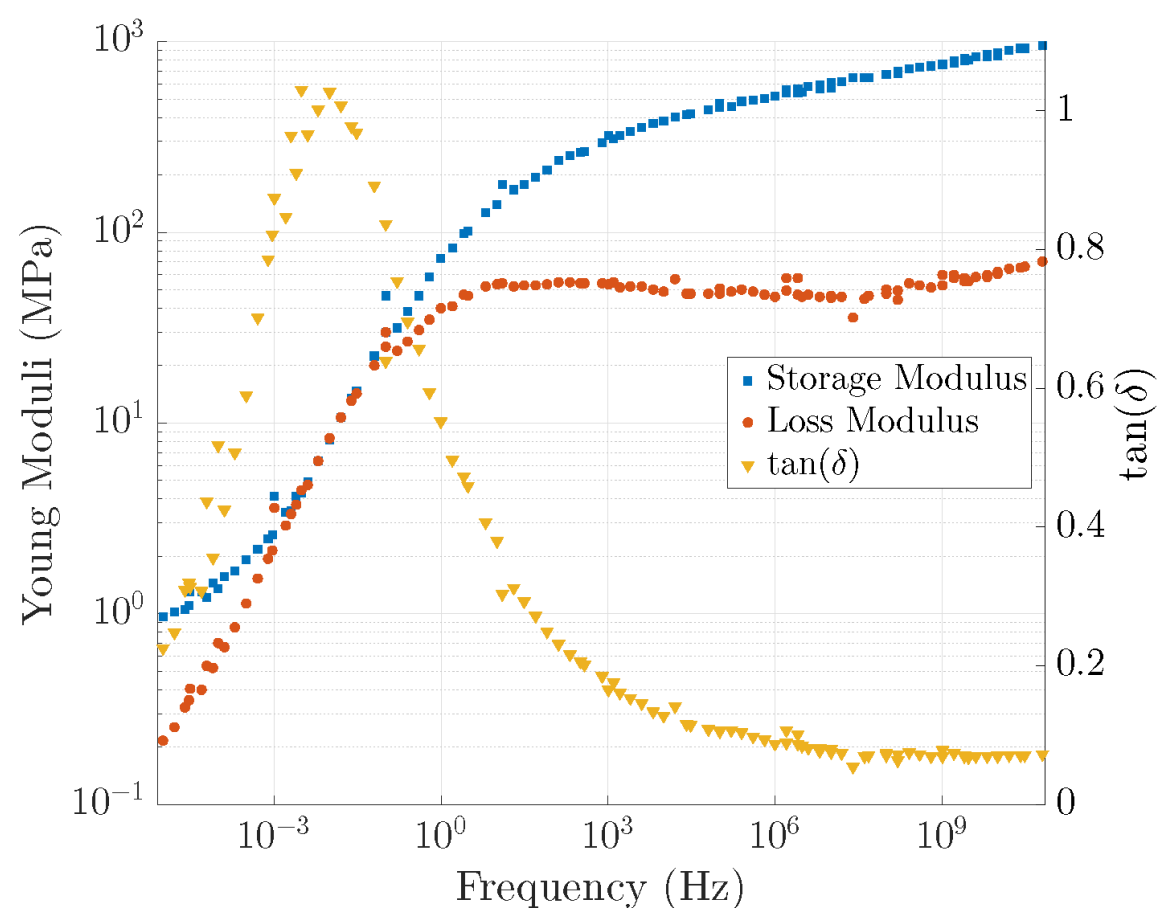

Figure 2: Small strain (0.01\%) dynamic response of PVB reconstructed through time temperature superposition with frequency ranging from $0.01 \mathrm{~Hz}$ to $1 \mathrm{~Hz}$ and temperature from $40{ }^{\circ} \mathrm{C}$ to $60{ }^{\circ} \mathrm{C}$ - reference temperature $20^{\circ} \mathrm{C}$.

DMA experiments were conducted at a strain amplitude of $0.01 \%$, spanning the temperature range $40{ }^{\circ} \mathrm{C}$ to $60{ }^{\circ} \mathrm{C}$ by $5^{\circ} \mathrm{C}$ steps, at 10 different frequencies between $0.1 \mathrm{~Hz}$ and 10 Hz. From time temperature equivalence, a master curve was built (reference temperature $20^{\circ} \mathrm{C}$ ) and is shown in Fig. 2. Maximal dissipation occurs at the glass transition which is found around $0.01 \mathrm{~Hz}$ at $20^{\circ} \mathrm{C}$. Roughly speaking, the glass transition temperature therefore lies around $30{ }^{\circ} \mathrm{C}$, slightly above room temperature as expected. In the glassy state, at low temperature/high frequency, Young's modulus is of the order of $1 \mathrm{GPa}$. It decreases as temperature increases/frequency decreases to reach about $1 \mathrm{MPa}$ in the rubbery state. 


\section{Large strain - uniaxial tension cycles}

To probe the large strain dynamics, cyclic experiments were conducted in uniaxial tension on PVB samples at different stretch rates and temperatures. The samples were stretched to $200 \%$ nominal strain $(\lambda=3)$, which is representative of the average stretch of the polymer ligament during steady-state delamination experiments on laminated glass. $\stackrel{[}{[}$

\section{Rate dependence}

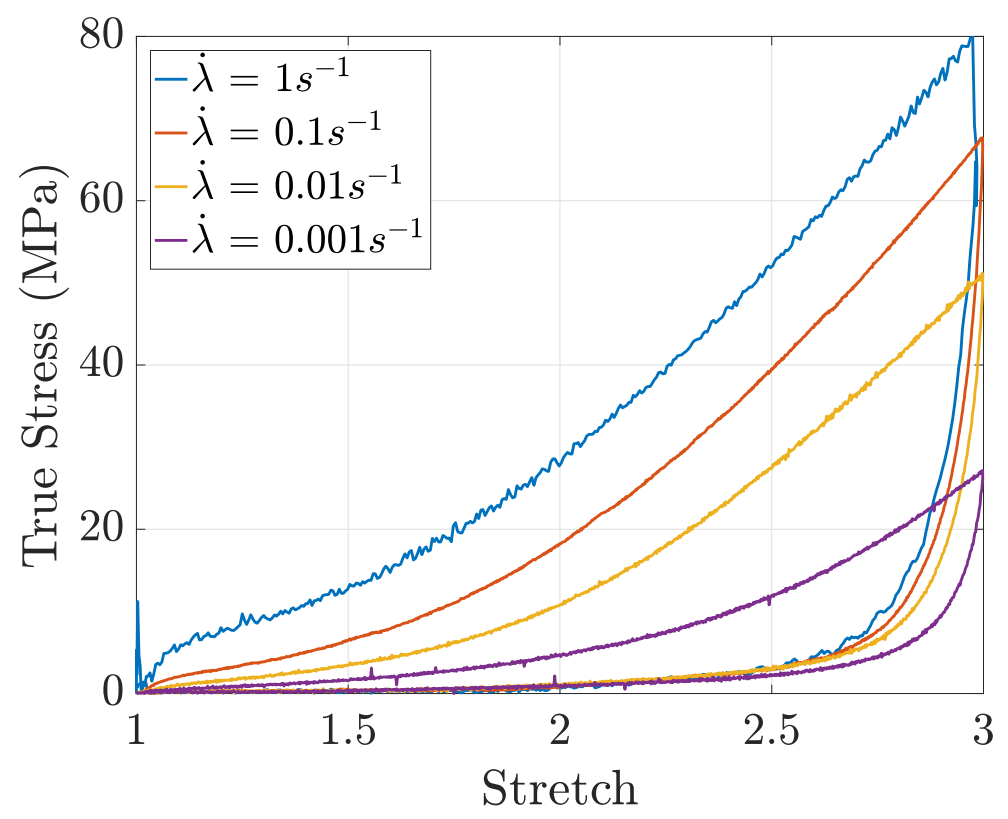

Figure 3: Large strain stress-stretch relation for PVB at $20^{\circ} \mathrm{C}$, for different stretch rates.

In Figure 3, the PVB stress-stretch response is plotted for four different stretch rates $\dot{\lambda}=0.001,0.01,0.1,1 \mathrm{~s}^{-1}$ at $20^{\circ} \mathrm{C}$. The overall stress level is much larger than expected for usual elastomers and the mechanical response depends significantly upon stretch rate. The low strain modulus, measured on the first $10 \%$ of strain, ranges from $7 \mathrm{MPa}$ at $0.001 \mathrm{~s}^{-1}$ to 80 MPa at $1 \mathrm{~s}^{-1}$, in agreement with small strain rheology measurements (Fig. 2). The material subsequently strain softens: the tangent modulus at a strain of $10 \%$ is typically lower than the modulus at very small strain. At most strain rates, this softening is gradual, but at the highest strain rate $\left(1 \mathrm{~s}^{-1}\right)$ a plastic like plateau appears at a higher stress level, extending 
between $10 \%$ to $30 \%$ nominal strain. At larger strains, stiffening sets in above a threshold strain which increases as strain rate decreases: at $1 \mathrm{~s}^{-1}$, strain stiffening is observed around $60 \%(\lambda=1.6)$ while at $0.001 \mathrm{~s}^{-1}$ it starts around $150 \%(\lambda=2.5)$.

As a result, the overall shape of the tension curves upon loading is highly non-linear, as already noted in the literature. ${ }^{714117}$ Similarity with the non-linear elastic response of elastomers, with marked stiffening at large strains has often been pointed out. However, several additional features are to be noted, which are not consistent with these models. First, as already mentioned, there is the plastic-like threshold appearing at large strain rates. $\frac{1118119}{}$ Second, the unloading curve, which is largely forgotten in the literature, drops steeply, which signals considerable energy dissipation. As estimated from the ratio of the areas measured under the unloading and the loading curves at the same strain rate, relative dissipation increases with strain rate and reaches $85 \%$ at $1 \mathrm{~s}^{-1}$. ${ }^{8}$ Interestingly, despite these two plastic-like features and the absence of chemical crosslinks, PVB does not present long term permanent deformation at ambient temperature: even starting from $200 \%$ strain, the initial sample size is fully recovered after unloading, but only following a remarkably long waiting time of typically ten minutes at room temperature. This is why there has been some confusion over the plastic nature of the mechanical response of PVB, and the plastic-like threshold observed at high strain rates is often called pseudo yield stress or overstress. ${ }^{17}$ Indeed, in the context of fracture or adhesion rupture, for all practical purposes, the very long time recovery is irrelevant, and PVB can aptly be considered viscoplastic.

\section{Temperature dependence}

In Figure 4, the PVB stress-stretch response is plotted for five different temperatures 10, 20, 30, 50 and $70^{\circ} \mathrm{C}$ at a constant stretch rate of $0.1 \mathrm{~s}^{-1}$. The non-linear PVB behavior features a complex dependence upon temperature. The evolution from 10 to $30^{\circ} \mathrm{C}$ parallels the evolution from high to low strain rates (Fig. 4) with a plateau at low temperature [resp. high strain rate] and a decrease of the overall stress level as temperature increases 


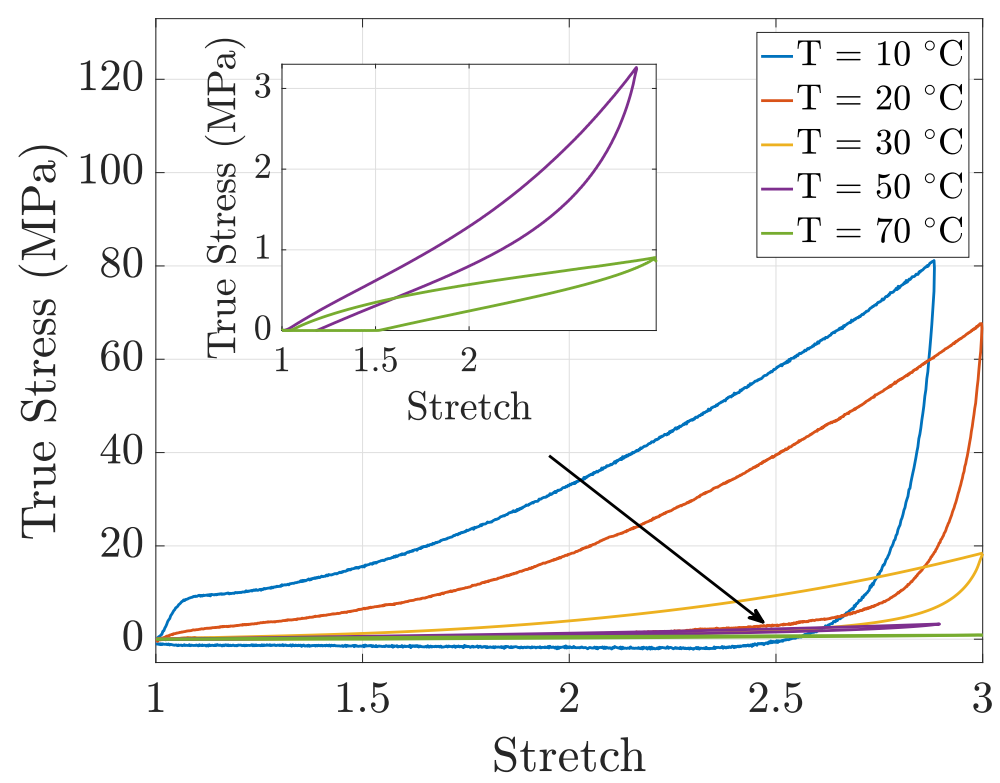

Figure 4: Temperature dependence of PVB large strain response in uniaxial tension cycles performed at $0.1 \mathrm{~s}^{-1}$ up to $200 \%$ deformation $(\lambda=3)$. The inset is a zoom for $T=50$ and $70^{\circ} \mathrm{C}$.

[resp. as strain rate decreases]. In this temperature range, some kind of time-temperature equivalence seems to hold for the large stretch regime. At $30^{\circ} \mathrm{C}$, the stress level has decreased strongly. Above $50^{\circ} \mathrm{C}$ (inset), the stress level is even lower, the dissipation cycle has nearly disappeared and there is now permanent deformation after unloading. The polymer behaves as a viscoelastic material with no long time elasticity, i.e. a Maxwell fluid.

\section{Thermal properties - a second transition}

The structure was further investigated with DSC experiments. Cooling and heating were conducted at $20^{\circ} \mathrm{C} \cdot \mathrm{min}^{-1}$. Three temperature cycles were successively applied to the same piece of PVB of $7.3 \mathrm{mg}$ (Figure $5 \mathrm{a}$ ):

1. the polymer is cooled down from room temperature to $-30^{\circ} \mathrm{C}$ and subsequently heated from -30 to $120^{\circ} \mathrm{C}$ (blue curve).

2. the polymer is cooled down again from 120 to $-30^{\circ} \mathrm{C}$. Then a heating ramp is applied on the sample up to $120^{\circ} \mathrm{C}$ (red curve). 

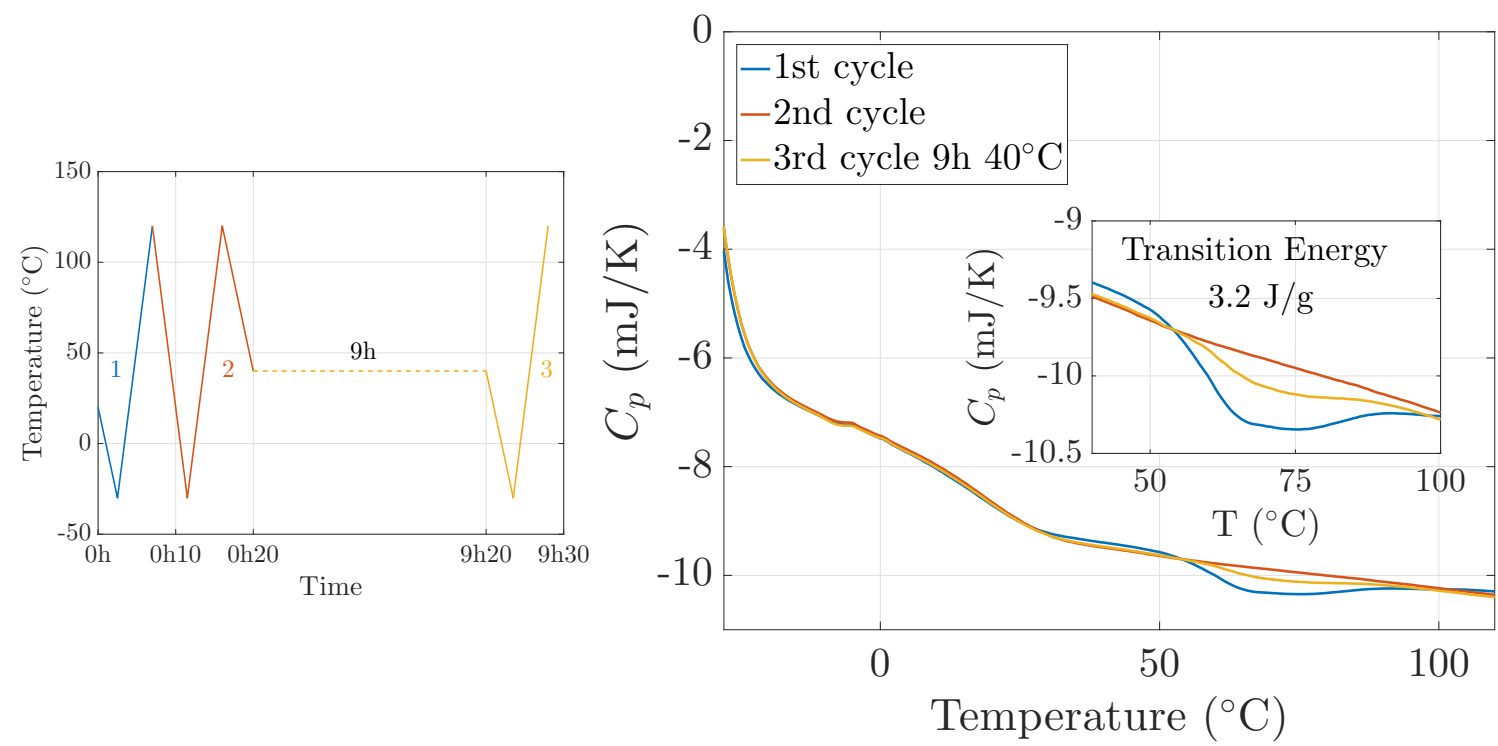

Figure 5: Thermal characterization of PVB with three successive temperature ramps - a: thermal history; b: heat capacity

3. the polymer is cooled down again from 120 to $40^{\circ} \mathrm{C}$ and the sample is maintained at this temperature for $9 \mathrm{~h}$ before cooling is resumed down to $-30^{\circ} \mathrm{C}$. Finally a third heating ramp (yellow curve) is applied from -30 to $120^{\circ} \mathrm{C}$.

In Figure 5, the heat capacity measured during the heating ramps of the three cycles is plotted as a function of temperature. During the first heating ramp (blue), the inflection in the curve around $27^{\circ} \mathrm{C}$ corresponds to a rather wide glass transition, also observed in the DMA measurements (Fig. 2). In addition, during this first heating ramp, a large exothermic bump appears between 50 and $90^{\circ} \mathrm{C}$. This exothermic signal seems to parallel the transition observed in the large strain experiments. It may be ascribed to a second transition, probably affecting the more strongly bonded second phase. During the second heating ramp performed in rapid succession after the first (red), the first transition is still observable, but the second transition cannot be seen anymore. However, in the third heating ramp, after annealing the sample $9 \mathrm{~h}$ at $40^{\circ} \mathrm{C}$ (yellow), the second transition is partially recovered, which may be ascribed to a process similar to ageing. 


\section{Deformation of the mesostructures upon stretching}

For the small and wide angle X-ray scattering (SAXS-WAXS) experiments, the samples were stretched up to $300 \%$ nominal strain $(\lambda=4)$ at $0.01 \mathrm{~s}^{-1}$ at 23 and $70{ }^{\circ} \mathrm{C}$. The measured scattering curves in the directions parallel and perpendicular to elongation are plotted in figure 6. We distinguish three $\mathrm{Q}$ ranges for the analysis. At large scattering vector $(Q>$ $0.3 \AA^{-1}$ ), the intensity curves exhibit a broad peak around $1 \AA^{-1}$ in both directions, typical of amorphous materials. There is no sign of crystallinity and this peak remains unaffected by tension. A second correlation peak at $Q=0.4 \AA^{-1}$ is also present and unaffected by elongation but its origin remains unclear. In the low $\mathrm{Q}$ range $\left(Q<0.01 \AA^{-1}\right)$ the unstretched sample presents a decrease in intensity scaling as $I \propto Q^{-3.5}$ which is likely to arise from large scale inhomogeneities in the system and micro cracks. As the sample is stretched, this low $Q$ scattering is unaffected in the direction perpendicular to strain and increases in the parallel direction developing a broad shoulder at $Q=0.007 \AA^{-1}$. Such behavior shows that the stretch structures PVB with a characteristic length scale of $c a 100 \mathrm{~nm}$. We now focus on the middle $\mathrm{Q}$ range $\left(0.01<Q<0.3 \AA^{-1}\right)$. In this $\mathrm{Q}$ range, the scattering curves for the unstretched sample present a broad shoulder around $Q=0.07 \AA^{-1}$ which may come from the $\mathrm{OH}$ rich domains. As the sample is stretched this signal evolves significantly in the direction parallel to elongation whereas the perpendicular component changes but slightly. As a consequence, these results reflect the stretching of $\mathrm{OH}$ rich domains present in PVB.

In order to quantify this stretching we have chosen to model the scattering curves within this $Q$ range by a Debye-Bueche model which describes the scattering from phase separated systems. In this model, correlations are characterized by a characteristic length $\xi$ and a pair

correlation function given by ${ }^{20}: \gamma(r)=\exp \left(-\frac{r}{\xi}\right)$. The resulting scattering cross section is given by:

$$
\frac{d \Sigma}{d \Omega}=\frac{8 \pi \Delta \rho^{2} \phi \xi^{3}}{\left(1+(Q \xi)^{2}\right)^{2}}
$$

where $\Delta \rho$ is the electronic contrast factor and $\phi$ is the volume fraction. 
Such model does not allow to describe the low $Q$ decrease in intensity which may arise from large scale homogeneities in the system and micro cracks. In order to take into account this contribution, we add to the Debye-Bueche model a Porod scattering term:

$$
\frac{d \Sigma}{d \Omega}=\frac{8 \pi \Delta \rho^{2} \phi \xi^{3}}{\left(1+(Q \xi)^{2}\right)^{2}}+\frac{A}{Q^{n}}
$$

As shown in figure 7, this model allows to get a good fit of the experimental data and defines two correlation lengths in the direction parallel and perpendicular to the stretch denoted $\xi_{\text {ortho }}$ and $\xi_{\text {para }}$. The evolution of these two quantities plotted in figure 8 shows that $\xi_{\text {para }}$

increases linearly with $\lambda$ from its unstretched value $\left(\xi_{\text {para }}(\lambda=1)=8 \AA\right)$ and reaches $33 \AA$ for the maximum elongation. Regarding the the evolution of the structure in the direction perpendicular to the stretch, we observe that $\xi_{\text {ortho }}$ is rather insensitive to the elongation which shows at the molecular scale that the deformation of this nanostructure is not affine, which suggests it is not elastic, but rather connected to plasticity. The same experiment was conducted at $70^{\circ} \mathrm{C}$. The spectra for the unloaded material were identical at $70^{\circ} \mathrm{C}$ and room temperature, and no significant change was observed either as PVB was stretched at $70^{\circ} \mathrm{C}$.

\section{Birefringence - segmental orientation in the chain network}

In the birefringence experiments, the measured intensity is homogeneous across the active part of the sample. It oscillates between bright and dark fringes with increasing stretch (Figure 9). These oscillations reveal a continuous increase of the induced optical anisotropy, which is measured through the birefringence order, i.e. the number of bright fringes observed during stretching. The initial state with an isotropic material at $0 \%$ strain $(\lambda=1)$ corresponds to a bright fringe with birefringence order $N=0$. In Figure 10, the birefringence (left) and birefringence order (right) recorded during uniaxial tension is plotted as a function of stretch for different temperatures and stretch rates. At $70^{\circ} \mathrm{C}$ the birefringence order increases slowly up to $N=3$ at $310 \%$ nominal strain $(\lambda=4.1)$ in a manner which 

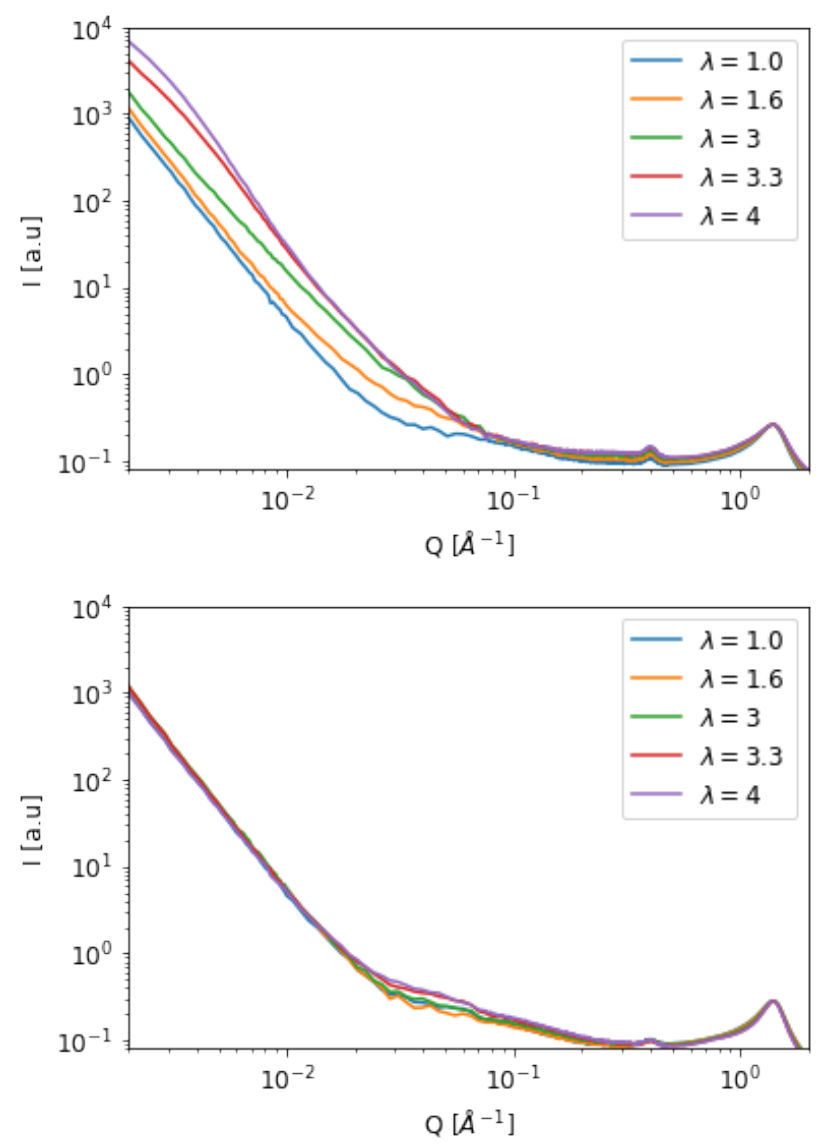

Figure 6: SAXS/WAXS spectra of PVB stretched at $\lambda=1,1.6,3,3.3,4$ at $23^{\circ} \mathrm{C}$ in the direction of the elongation (top) and perpendicular to it (bottom).

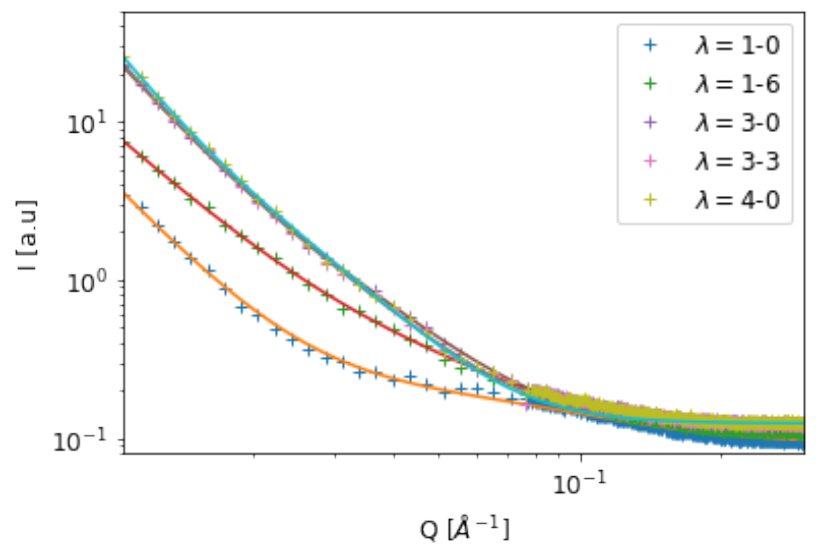

Figure 7: SAXS-WAXS spectra of PVB stretched at $\lambda=1,1.6,3,3.3,4$ at $23^{\circ} \mathrm{C}$ in the direction of the elongation. The solid lines correspond to the best fits defined by equation 2 . 


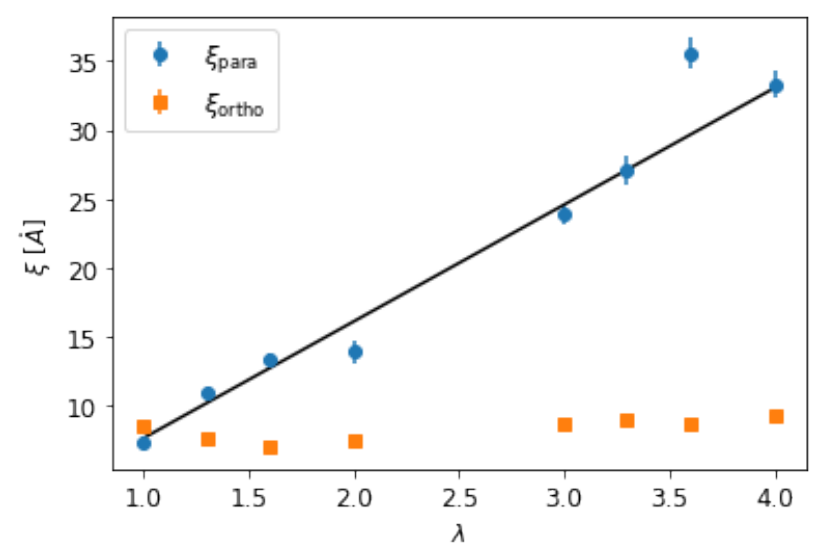

Figure 8: Evolution of $\xi_{\text {para }}$ and $\xi_{\text {ortho }}$ as a function of $\lambda$ at $23^{\circ} \mathrm{C}$ in the direction of the elongation. The solid line corresponds to a linear function which slope is 1 .

parallels the stress-stretch relation (Fig. 4). At lower temperatures, for an identical strain rate, the birefringence order rises more markedly, but is not proportional to stress: stress increases more rapidly at large stretches (Fig. 3), analogous to a stiffening material, while birefringence follows the opposite trend and slackens at larger stretches. As with stress, there is a moderate impact of stretch rate on birefringence.

To throw more light on the effects of strain rate and temperature, more complex types of loadings were considered. Figure 11 describes the concomitant evolution of the stress response and the birefringence signal during a stress relaxation test: the interlayer is first stretched to $200 \%$ nominal strain $(\lambda=3)$ at $20^{\circ} \mathrm{C}$ at a constant stretch rate $0.01 \mathrm{~s}^{-1}$, then the macroscopic stretch is kept constant during 1000 s. During loading, both stress and birefringence signal increase as described previously, with birefringence reaching the order $N=7$. During the hold period, however, stress decreases significantly with time, losing more than $80 \%$ of its initial value after $1000 \mathrm{~s}$ as a result of viscoelastic dissipation. Birefringence, however, does not evolve significantly and the birefringence order barely loses half a unit (down from 7) over the same period of time. This experiment confirms that in PVB, in contrast to elastomers, 21 the birefringence signal is largely decoupled from macroscopic stress.

In a different relaxation experiment, the same mechanical history is applied with loading 


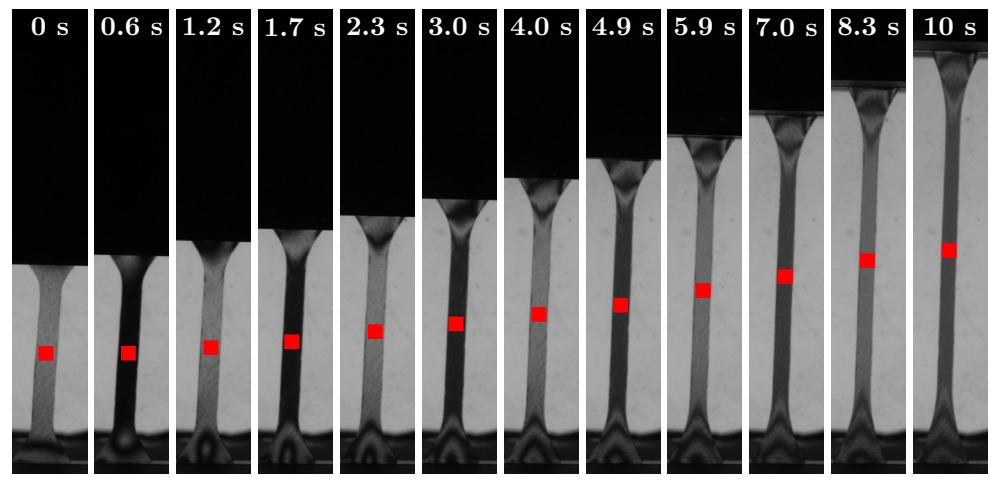

(a)

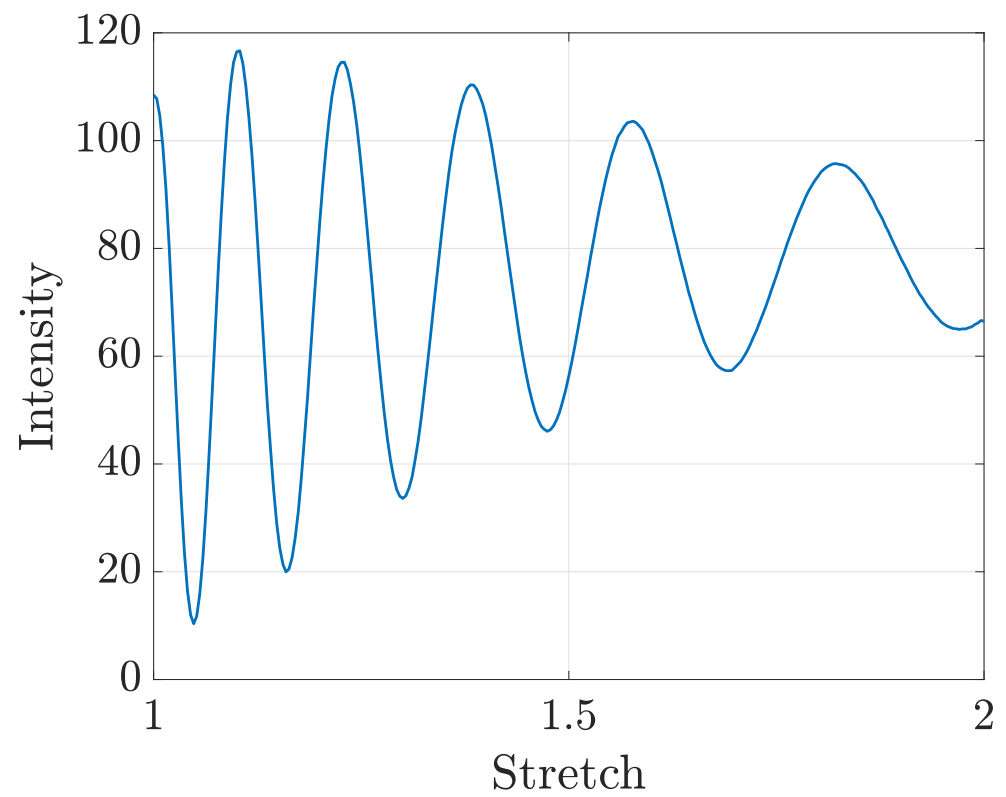

(b)

Figure 9: Birefringence experiment during uniaxial tension of PVB at a constant stretch rate of $0.1 \mathrm{~s}^{-1}$ and a temperature of $20^{\circ} \mathrm{C}$. (a) Full size imaging of the stretched sample through crossed polarizers. (b) Time evolution of the birefringence signal in a point located in the middle of the sample (corresponding to the red spot). The birefringence order is given by the number of bright fringes successively observed before reaching a given stretch. 

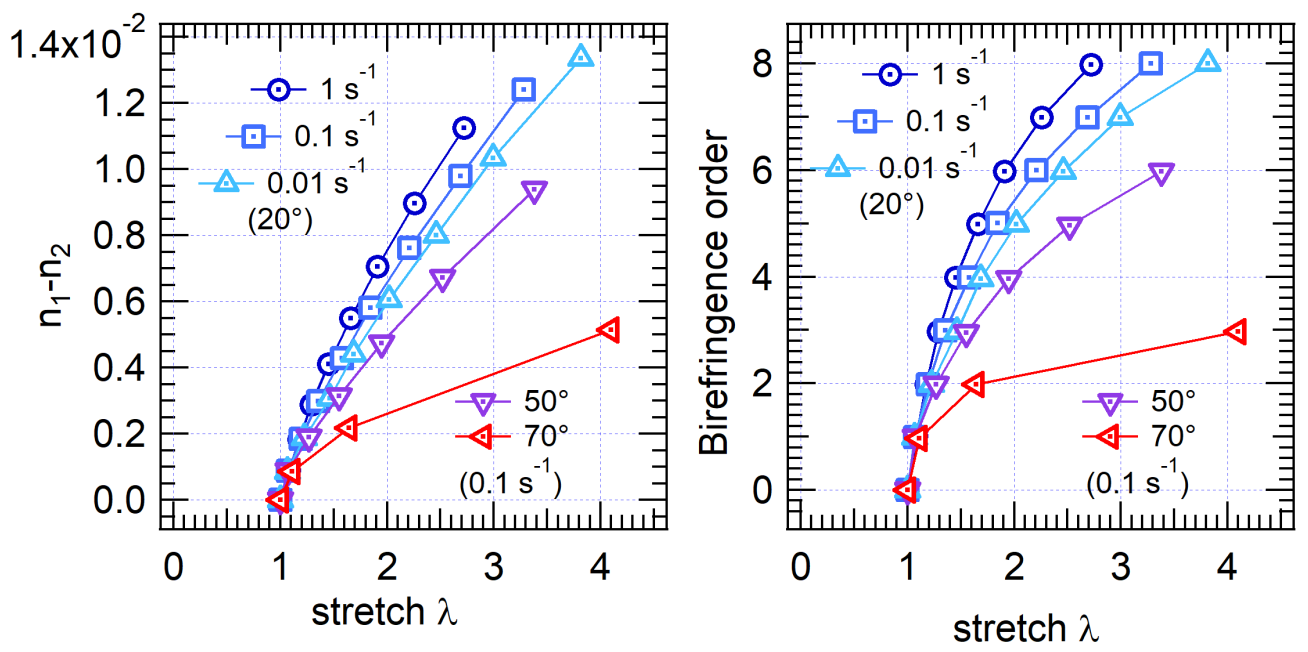

Figure 10: Birefringence $\left(n_{1}-n_{2}\right)$ (left) and fringe order $N$ (right) as a function of stretch $\lambda$. The birefringence was calculated from the relation $\left(n_{1}-n_{2}\right) h_{0}=N l_{\text {opt }} \sqrt{\lambda}$ to account for sample thinning at constant volume. It is strongly dependent upon temperature and moderately dependent upon stretch rate, but not proportional to stress.

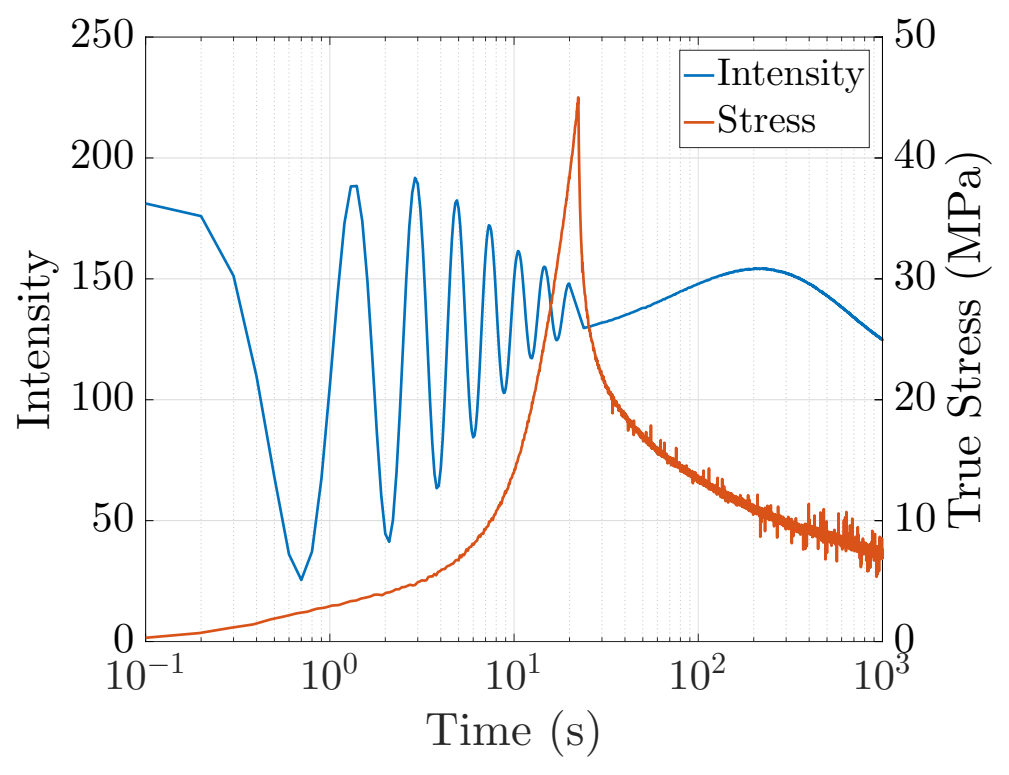

Figure 11: After loading at $20^{\circ} \mathrm{C}$ and $0.01 \mathrm{~s}^{-1}$ stretch rate, the strain is kept constant at the maximal value of $200 \%(\lambda=3)$. Stress is found to relax rapidly while birefringence order changes only by about half a unit. 
followed by a hold period. In addition, after a waiting time of $500 \mathrm{~s}$, during which stress has relaxed considerably, temperature is raised to $50^{\circ} \mathrm{C}$ (Figure 12), at the onset of the second transition. Upon annealing at constant stretch, strong intensity oscillations reappear, suggesting a reversed succession of birefringence fringes. Counting the fringes, we find that $1000 \mathrm{~s}$ after the temperature jump to $50^{\circ} \mathrm{C}$, the birefringence order $N$ has decreased from 7 to 4 . If the same experiment is carried out at $70^{\circ} \mathrm{C}$, well into the second transition, $N$ decreases from 7 to 2 . These results show that segmental orientation is significantly relaxed as the second transition is reached.

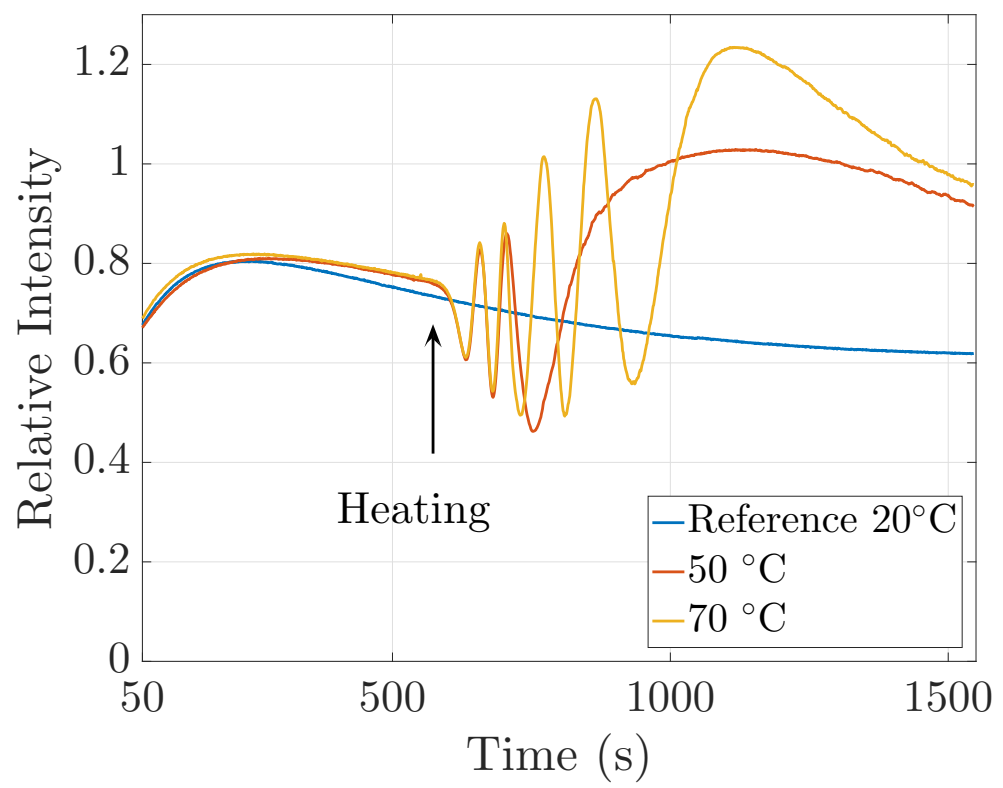

Figure 12: Relaxation with temperature step: birefringence is reduced when temperature is raised from $20^{\circ} \mathrm{C}$ to $50^{\circ} \mathrm{C}$ or $70^{\circ} \mathrm{C}$ during the hold period.

\section{Discussion}

\section{PVB mechanical response - standard description}

The overall shape of the stress-strain curve exhibits first softening then stiffening at larger strains (Fig. 3). Because of this characteristic shape, PVB is typically described as an hyperelastic material where network stretching becomes increasingly difficult as the chains 
are pulled taught, from which stiffening results. To implement a constitutive relation, this hyperelastic behaviour is usually coupled to a Prony series accounting for viscoelasticity, with strain rate dependence (Fig. 3) and stress relaxation (Fig. 11). ${ }^{7114117}$ In the case of PVB, however, this description hits upon two limitations.

\section{Birefringence}

In hyperelasticity, statistical molecular orientation is induced by the stretching of randomly oriented chains that are considered loose between network crosslinks. Segmental orientation drives entropy reduction (and thus elasticity) as well as birefringence. Birefringence is therefore expected to be proportional to stress, as found e.g. in elastomers, even in the stiff-

ening regime. ${ }^{222}$ In contrast, in our experiments, birefringence and stress are decoupled. At larger stretch, birefringence slackens when stress picks up (Fig. 10), and at constant stretch, birefringence remains stable while stress relaxes (Fig. 11).

\section{Plastic-like features}

In addition to such peculiarities in the birefringence signal, plastic-like features in the macroscopic mechanical response are apparent, which cannot be accounted for by a hyperelastic based model. Such is the case for: 1) the apparent yield threshold and plateau observed at higher strain rates (Fig. 3) or lower temperatures (Fig. 4)and 2) the steep load drop upon unloading (Fig. 3) and ensuing dissipation cycle.

\section{Structure and deformation in PVB}

Based on the structure of plasticized PVB proposed in the literature and our experimental results, we propose a different viewpoint on the relation between structure and mechanical response in PVB. 


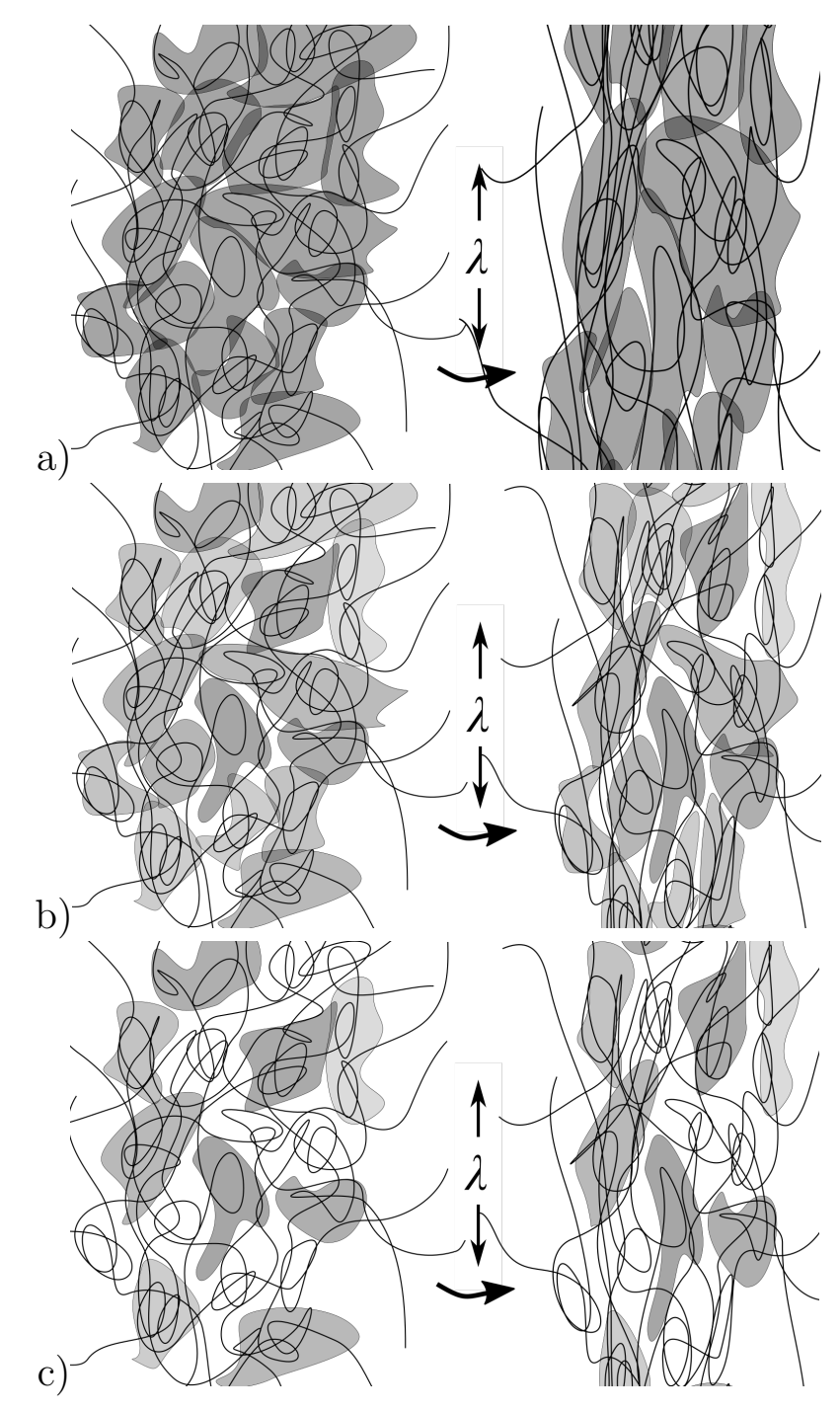

Figure 13: Schematic view of the heterogeneous structure sharing the same PVB macromolecules, following Schaefer et al. $\stackrel{[16}{ }$ The grey second phase domains present a high density of H-bonds, they are stiffer and with a reduced mobility (the various shades of gray here reflect some variability in the exact structure and dynamics), while the white domains contain fewer H-bonds, more plasticizer and are softer. Upon stretching, the deformation of the domains result in anisotropic response in the SAXS-WAXS signal (Fig. 6). At low temperature $\left(10^{\circ} \mathrm{C}\right)$ or high strain rate, the stiffer domains percolate (a). At room temperature and moderate strain rate, close packing implies significant deformation of the stiff domains during stretching (b) and the material retains most of its plastic nature, with high stress levels, strain hardening and birefringence induced by molecular orientation during plastic like flow. At elevated temperature $\left(70^{\circ} \mathrm{C}\right)$, packing is looser, and the material responds as a loosely crosslinked viscoelastic matrix (c). 


\section{PVB structure - phase separation}

From NMR experiments, Schaefer et al. ${ }^{[16}$ showed that plasticized PVB is a phase-separated material: schematically, they propose 1) a phase of diluted polymer chains with high plasticizer content, with a faster dynamics; 2) a second phase with a lower plasticizer content and a slower dynamics (Fig. 13). Moreover, based on an analysis of position fluctuations, they suggest that the relative motion of the slow domains is restricted, for example by compact packing. Based on NMR experiments, Mertz ${ }^{23}$ confirmed that higher plasticizer content results in higher phase segregation.

Our SAXS-WAXS data (Fig. 7) are consistent with this description of a two phase polymeric system presenting different characteristic sizes. The largest scales are responsible for the $q^{-n}$ with $n \simeq 3.5$ decrease in scattered intensity. A shoulder appears and moves to lower wave vectors with stretch, culminating in typical sizes around $100 \mathrm{~nm}$ at maximum stretch. We also showed that a smaller characteristic length scale denoted $\xi$ of around $1 \mathrm{~nm}$ is present and reflect $\mathrm{OH}$ rich domain. Upon streching $\xi$ increases linearly with $\lambda$ in the direction parallel to the stretch and remains constant in the perpendicular direction, reflecting structural distortions upon stretching, which we tentatively ascribe to plastic rearrangements.

\section{Structure and dissipation}

In PVB, the polymer chains are not chemically crosslinked, but physically connected through the stiffer second phase domains which consist of clusters of H-bonds. ${ }^{16 \mid 24}$ Similar structures are found in polyurethanes and polyureas and in general in materials combining flexible chains and hydrogen bonding capable groups. $\frac{25}{25}$ More generally H-bonds in hydrophobic elastomers are known to increase mechanical stiffness due to formation of a supramolecular physical bond network. $\frac{26}{28}$ H-bonds also increase the dissipated energy during stretching due to multiple breaking and reforming events. ${ }^{29}$ Indeed, keeping in mind this structure of strongly interconnected second phase domains within a more mobile matrix (Fig. 13), it readily appears that macroscopic stretching will also involve local accommodation of the 
stiffer and slowly relaxing domains, as shown for example by the SAXS-WAXS data (Fig. 6). Plastic deformation and rearrangement of the stiffer second phase domains are energetically costly operations which necessarily develop high stress levels and result in a highly dissipative material. Also, when holding the material at constant stretch, fast rearrangements in the more mobile domains result in stress relaxation (Fig. 11). Similarly, due to the heterogeneity of the dynamics in the structure and the presence of mobile domains, there is no apparent initial yield threshold at room temperature for slow or moderate strain rates.

\section{Strain hardening}

In this context, the characteristic non-linearity of the stress-stretch relation and its temperature dependence naturally emerge as a consequence of plastic strain hardening. Indeed, it is well known that in glassy polymers, plastic flow induces local molecular orientation which

in turn limits further creep, resulting in strain hardening. $\frac{30131}{3}$ This mechanism is different in nature from the stiffening due to finite extensibility of the chains in elastomeric networks, although both produce rather similar shapes for the stress-stretch curves upon loading. Yet the prefactor is larger, with larger stress levels for strain hardening in glassy polymers, and has an inverse temperature dependence, as it decreases with increasing temperature, matching our experimental results.

\section{Flow induced birefringence}

Similarly, in the plastic creep perspective advocated here, chain orientation results from the plastic-like flow in the stiff domains. Indeed, this process generates not only strain hardening, but also birefringence. ${ }^{32}$ It is interesting to note that in this case, the quantity readily associated with birefringence is creep strain, and not stress as in the stretching of an elastomeric network. The measured birefringence (Fig. 10) is consistent with typical values registered for viscous flow of dense polymers such as PMMA ${ }^{33}$ for example. Interestingly, this creep flow mechanism for birefringence is also consistent with the slackening of birefringence observed 
in our experiments at large strains. While in the chain stretch mechanism, birefringence increases more rapidly at larger stretches, proportionally to stress, $\stackrel{22}{22}$ with strain hardening, creep flow becomes more difficult as stretch increases, which is expected to moderate further increase of orientation, while requiring increasingly higher stresses. Higher strain rates are expected to produce more orientation and more birefringence, while temperature is expected to work the other way round, as observed (Fig. 10).

\section{Impact of temperature}

Above $c a .50^{\circ} \mathrm{C}$, DSC evidences a second transition (Fig. 5), residual strain appears (Figs. 3 and 4) and birefringence is strongly reduced (Fig. 12). At ambient temperature, stretching induces distorsions in the microstructure, but this is no longer the case at $70^{\circ} \mathrm{C}$. These observations suggest that the strong associativity due to H-bonds $\frac{16 \mid 34}{16}$ has been overcome, and that the second phase, which is stiffer at lower temperatures, softens at the second transition. PVB then behaves more like an entangled polymer melt, with a strong decrease of dissipation (Fig. 13 c) and flows without terminal elasticity, analogous to a viscoelastic Maxwell fluid. However, the second transition is not of the order/disorder type. Indeed, we

find that the SAXS-WAXS data in the unstretched state are identical at room temperature and at $70^{\circ} \mathrm{C}$, suggesting that the same microphase separated state is present both above and below the second transition temperature. On a mechanical viewpoint, the transition rather corresponds to percolation of domains undergoing a reduction of mobility as temperature decreases: when lowering the temperature to $10^{\circ} \mathrm{C}$, the macroscopic response clearly exhibits a yield threshold which marks the percolation of the stiffer second phase domains (Fig. 13 a).

\section{A creep based numerical scheme for the non-linear response of PVB}

For a better qualitative understanding of the plastic deformation mechanism of PVB at ambient temperature and the associated dissipation pathway at large strain, we propose 
a simple constitutive model, the schematics for which is shown in Fig. 14. Quantitative calibration of the model or inclusion of thermal effects are beyond the scope of this paper.

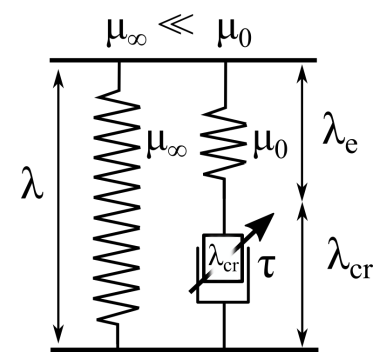

Figure 14: Qualitative rheological model. Material non linearity relies on the dashpot element, which is strain dependent.

We introduce two branches in the model: the first branch is purely elastic and ensures full shape recovery at long term. This "backspring" is taken as compliant, because the characteristic time for recovery is large. In the second branch, the modulus is much larger, accounting for the large instantaneous stiffness of the material and there is a creep element, introducing time dependence. Note that similar creep based descriptions of PVB have sporadically been evoked in the literature. 35

Numerically, the model is implemented following standard viscoplastic descriptions of polymers. $\frac{136[37}{137}$ With the decomposition of the deformation gradient into elastic and creep deformation $\boldsymbol{F}=\boldsymbol{F}^{e} \cdot \boldsymbol{F}^{c r}$, we assume the plastic stretch rate has the form $\boldsymbol{D}^{c r}=\dot{\bar{\epsilon}}^{c r} \frac{3}{2 \bar{\sigma}^{\prime}} \boldsymbol{\sigma}^{\prime}$ where $\boldsymbol{\sigma}^{\prime}$ is the deviatoric Cauchy stress, $\bar{\sigma}^{\prime}=\sqrt{\frac{3}{2} \sigma_{i j}^{\prime} \sigma_{i j}^{\prime}}$ is the equivalent deviatoric Cauchy stress and $\dot{\bar{\epsilon}}^{c r}$ is the equivalent creep strain rate. The creep deformation can be calculated by integration of the plastic stretch rate using standard methods ${ }^{36}$. Using the long time modulus $\mu_{\infty}$ and the creep time $\tau$, we introduce a small strain material viscosity $\eta=\mu_{\infty} \tau$ and write the equivalent creep strain rate

$$
\dot{\bar{\epsilon}}^{c r}=\frac{\bar{\sigma}^{\prime}}{\eta g(\lambda)}
$$

where $g(\lambda)$ is a dimensionless, increasing, function of stretch $\lambda$ with $g(1)=1$. As such, $\eta g(\lambda)$ is an effective viscosity which will account for the strain dependence of the creep process. 
For the numerical example shown below, we define

$$
g(\lambda)=\exp \left(\sqrt{\frac{I_{1}^{c r}-3}{J_{m}}}\right)
$$

where $I_{1}^{c r}=\boldsymbol{I}: \boldsymbol{C}^{c r}$ is the first invariant of the right Cauchy-Green creep strain tensor $\boldsymbol{C}^{c r}=\boldsymbol{F}^{c r T} \cdot \boldsymbol{F}^{c r}$ and $J_{m}$ is the characteristic hardening strain. The stretched exponential form is phenomenological, a loose reminiscence of Demiray's exponential model for the non-

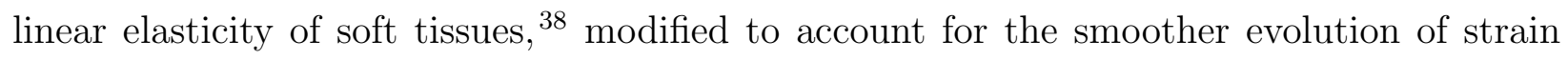
hardening observed in the present experiments.

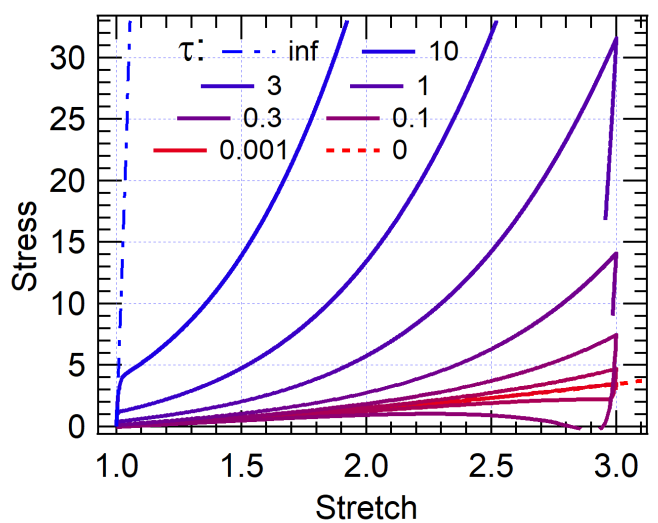

a)

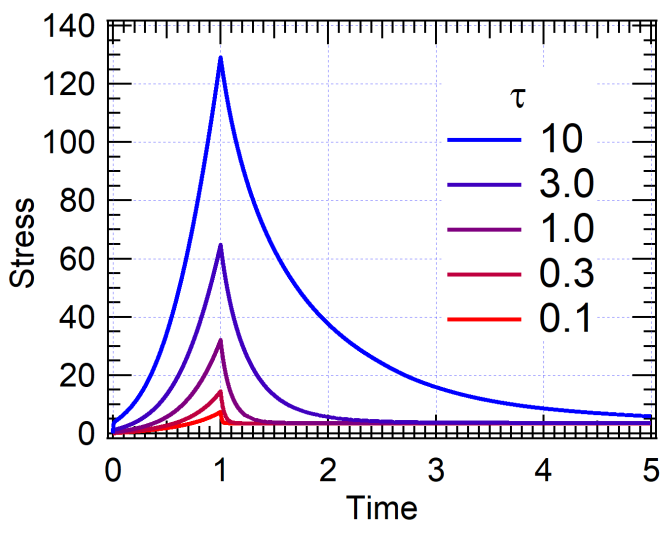

Figure 15: Creep based numerical model with strain hardening: a) stress-stretch relation with various creep times and constant loading time. The limit cases are elastic with the short time $(\tau=\infty)$ or long time modulus $(\tau=0)$; b) stress relaxation curves for the same parameters.

In Fig. 15, we show a series of numerical results for a value of the short time modulus 
$\mu_{0}=1$ and a ratio $\mu_{0} / \mu_{\infty}=500$. The elastic potentials are neo-hookean, so that the elastic contributions themselves contain no stiffening mechanism. The characteristic creep strain for hardening in Eq. 4 is $J_{m}=5.0$. The geometry is uniaxial tension on a thin strip and loading-unloading takes place at constant velocity within 1 unit of time. This is equivalent to investigating one material with fixed creep time $\tau$ and proportionally changing the strain rate, spanning the full dynamic range. For $\tau=0$ (or infinitely low strain rate), the response is reversible and we obtain the long time elastic response (first branch). For $\tau=\infty$ (or infinitely high strain rate), the response is also reversible, and we obtain the short time elastic response (dominated by the elastic element of the second branch). For intermediate values of $\tau$ (or strain rate), stress takes off smoothly at small strains. There is finite creep, which gives rise to the typical non-linear response found experimentally (Fig. 3). The pronounced non-linearity is due to strain hardening, not to stiffening in some elastic-like stretching of the polymeric network. It appears at increasingly large stretches as strain rate (or $\tau$ ) decreases. After unloading, full recovery of the original material shape is obtained at long times. These features are consistent with the experimental observations (Fig. 3).

For the larger strain rates ( $\tau=3$ and 10 time units), creep as dictated by Eq. 3 sets in when instantaneous elastic stresses have already built up, which is manifest in the appearance of a plastic-like threshold. It is also important to comment that we have not explicitly introduced a yield threshold in the model: the (pseudo) yield stress arises naturally in the model without additional parameters. In parallel, a sharp drop also appears upon unloading, as found experimentally (Fig. 3) especially for the larger strain rates. We have also calculated relaxation curves (Fig. 15 b). Strong relaxation is found, again in agreement with the experiments. The magnitude of the stress relaxation, like the steep unload curve, actually stems from the large value of the ratio $\mu_{0} / \mu_{\infty}$. Moreover, the relaxation process is clearly stretch dependent, since it is not single exponential in shape. As expected, it is much faster at small strains than at large strains.

There are also a number of shortcomings in this minimal model. First of all, no tem- 
perature effect has been included. More significantly, due to the very simple structure of the hardening function $G(\lambda)$, hardening is not permanent and will decrease as creep strain decreases. This phenomenon is particularly clear in the calculated loading-unloading curves for $\tau=0.001$ and 0.1 time unit which soon revert to the long time elastic limit as the small creep strain vanishes upon unloading. For the larger values of characteristic creep time $\tau$ tested here, creep strain is much more considerable and stress unloads to zero (and even becomes compressive) upon unloading. For clarity, the final stages of unloading have not been shown on the figure for the larger values of $\tau$.

In summary, the present numerical scheme features all the major characteristics of the dynamic response of PVB at large strains. It remains very simple as it contains only three elements (a variation over the so-called standard model) and the only element of complexity is the strain dependent viscosity in the newtonian-like creep term. For more quantitative fits to experimental data, several immediate generalizations lie at hand. Other branches with different characteristic times (and if needed hardening) may be added, reflecting different deformation processes. The model parameters may also depend upon temperature. The simple newtonian-like form of creep can directly be generalized to a Norton-Hof type process with $\dot{\bar{\epsilon}}^{c r}=\frac{1}{\tau G(\lambda)}\left(\frac{\tilde{q}}{\mu_{\infty}}\right)^{m}$ where $m$ is the Norton-Hoff exponent, here taken equal to 1 . Finally, stronger coupling with the evolution of the structure with stretch could be introduced through a damage variable.

\section{Architecture of a dissipative polymeric material}

Structural heterogeneity is known to enhance dissipative properties, for example in natural rubbers, silicones and acrylic adhesives. In pressure sensitive adhesives, it has been shown to correlate favourably with adhesion properties. ${ }^{39}$ For the strengthening of weak gels, double network structures with an underlying stretchy network filled by a more dissipative, plastic like second phase provide a large distribution of time scales and improved stretch resistance. ${ }^{40}$ Chemically interacting nanoparticles dispersed in gel networks may play an analogous role. $\stackrel{41}{ }$ 
Even closer in terms of both structure and response are the polyampholyte gels characterised by a wide distribution of ionic bond clusters. ${ }^{42}$ Their deformation and rupture lie at the root of excellent toughness properties.

For PVB, microphase separation with interconnected domains, as illustrated in Fig. 13 , seems to adequately reconcile deformability with dissipation. The phase separation has been suggested by NMR $\frac{16}{[6}$ and diffraction (Ref ${ }^{16}$ and present work) but other methods such as AFM or TEM imaging could bring useful insight as well. As already mentioned, a similar microphase separated structure with soft and stiff domains is found in other polymers such as polyurea, 1 an elastomer with soft and hard segments bound by $\pi$ stacking and hydrogen bonding. This material features both deformability and strength. Damage incurred by the stiff phase is thought to contribute significantly to the overall material toughness. For PVB, deformability is obtained through the low effective modulus of the soft phase, with large distances between effective cross links. Dissipation is found in the plastic deformation of the stiff, strain hardening domains. With such a structure in mind, the major parameters that can be leveraged in materials engineering are likely the size of the stiffer, second phase clusters, their overall volume fraction and their energies of deformation and rupture. Adjusting these parameters through formulation and processing should allow optimization for specific applications.

\section{Conclusion}

Building upon the picture of PVB structure and dynamics provided by Schaeffer et al. $\frac{16}{16}$ thirty years ago, we have used a combination of thermal, mechanical, birefringence and SAXS-WAXS experiments to investigate the macromolecular structure and mechanical response of PVB under large amplitude stretching. The results shed light on the mechanisms behind the exceptional dissipative properties of PVB.

There is phase separation of the polymer network into two domains, tightly intercon- 
nected by bridging macromolecular chains. The plasticizer rich domains are soft while for temperatures below the second transition $\left(\mathrm{ca} 50^{\circ} \mathrm{C}\right)$ the $\mathrm{H}$-bond rich domains are stiff. In this regime, the mechanical response of PVB is clearly dominated by viscoplastic dissipation in the stiff domains. The large stresses needed to break and reform hydrogen bonds upon stretching are manifest in the large instantaneous elastic modulus and the high stress level needed to induce plastic-like flow, which are key to the large dissipation and high impact

performances. The existence of two transitions at close proximity in temperature/frequency also contributes to a wide dynamic spectrum and enhanced dissipation. The interconnected H-bond rich domains still form a percolating network with a low value of the long time elastic modulus reflected in the very long creep time back to zero stretch.

As a result, the mechanical response of plasticised PVB at room temperature can be accounted for by a creep based model in which the characteristic nonlinearity of the stressstretch curve at large stretches, due to strain hardening in the stiff phase and not network stiffening, is efficiently represented by a strain dependent viscosity (Eq. 3).

At elevated temperatures, however, the H-bond rich domains soften and the polymer can flow freely, which facilitates assembly of the glass laminates. Lowering the temperature below $50^{\circ} \mathrm{C}$, the stiff scaffold reforms, imparting structural integrity and impact resistance to the product.

It can be expected that the nature and size of the stiffer domains and the way they are interconnected are crucial to obtain the right balance of stretch and dissipation. The link provided here between rheological properties and macromolecular structure of PVB provides guidelines for better models of the interlayer response upon impact and for better design of the polymer.

\section{Acknowledgements}

We thank Alba Marcellan and Herbert Hui for interesting discussions and suggestions, and L. Olanier, A. Lantheaume and A. Fourgeaud for help with the experimental set ups. 


\section{References}

(1) Cho, H.; Rinaldi, R. G.; Boyce, M. C. Constitutive modeling of the rate-dependent resilient and dissipative large deformation behavior of a segmented copolymer polyurea. Soft Matter 2013, 9, 6319-6330.

(2) Bennison, S.; Jagota, A.; Smith, C. Fracture of Glass / Poly(vinyl butyral) (Butacite (®) laminates in biaxial flexure. Journal of the American Ceramic Society 1999, 82, $1761-1770$.

(3) Galuppi, L.; Royer-Carfagni, G. Laminated beams with viscoelastic interlayer. International Journal of Solids and Structures 2012, 49, 2637-2645.

(4) Hooper, P.; Sukhram, R.; Blackman, B.; Dear, J. On the blast resistance of laminated glass. International Journal of Solids and Structures 2012, 49, 899-918.

(5) Corroyer, E.; Brochier-Salon, M.; Chaussy, D.; Wery, S. Characteriszation of commercial polyvinylbutyrals. International Journal of Polymer Analysis and Characterization 2013, 18, 345-357.

(6) Arayachukiat, S.; Siriprumpoonthum, M.; Nobukawa, S.; Yamaguchi, M. Viscoelastic properties and extrusion processprocess of poly(vynil butyral). Journal of Applied Polymer Science 2014, 131, 40337-40344.

(7) Pelfrene, J.; Dam, S. V.; Paepegem, W. V. Numerical analysis of the peel test for characterisation of interfacial debonding in laminated glass. International Journal of Adhesion and Adhesives 2015, 62, 146-153.

(8) Elzière, P.; Dalle-Ferrier, C.; Creton, C.; Barthel, E.; Ciccotti, M. Large strain viscoelastic dissipation during interfacial rupture in laminated glass. Soft Matter 2017, 13, 1624-1633. 
(9) Samieian, M. A.; Cormie, D.; Smith, D.; Wholey, W.; Blackman, B. R.; Dear, J. P.; Hooper, P. A. On the bonding between glass and PVB in laminated glass. Engineering Fracture Mechanics 2019, 20, 518-525.

(10) Sha, Y.; Hui, C. Y.; Kramer, E.; Garret, P.; Knapczyk, J. Analysis of adhesion and interface debonding laminated safety glass. Journal of Adhesion Science and Technology 1997, 11, 49-63.

(11) Hooper, P.; Blackman, B. The mechanical behavior of poly(vynil butyral) at different strain magnitudes and strain rates. Journal of Material Science 2012, 47, 3564-3576.

(12) Seshadri, M. Mechanics of glass-polymer laminates using multi-length scale cohesive zone Models. Ph.D. thesis, Carnegie Mellon University, Department of civil and environmental engineering, Carnegie Mellon University, 2001.

(13) Juang, Y.-J.; Lee, L. J.; Koelling, K. W. Rheological analysis of polyvinyl butyral near the glass transition temperature. Polymer Engineering and Science 2001, 41, 275-292.

(14) Del Linz, P.; Hooper, P. A.; Arora, H.; Wang, Y.; Smith, D.; Blackman, B. R.; Dear, J. P. Delamination properties of laminated glass windows subject to blast loading. International journal of impact engineering 2017, 105, 39-53.

(15) Paul, C.; Cotts, P. Effects of aggregation and solvent quality on the viscosity of semidilute poly(vinyl butyral) solutions. Macromolecules 1986, 19, 692-699.

(16) Schaefer, J.; Garbow, J.; Stejskal, E.; Lefelar, J. Plasticization of Poly(butyral-co-vinyl alcohol). Macromolecules 1987, 20, 1271-1278.

(17) Hooper, P.; Blackman, B.; Dear, J. The mechanical behaviour of poly (vinyl butyral) at different strain magnitudes and strain rates. Journal of Materials Science 2012, 47, $3564-3576$. 
(18) Bennison, S.; Sloan, J.; Kistunas, D.; Buehler, P.; Amos, T.; Smith, C. Laminated glass for blast mitigation: role of interlayer properties. Glass processing days. 2005.

(19) Zhang, X.; Hao, H.; Shi, Y.; Cui, J. The mechanical properties of Polyvinyl Butyral (PVB) at high strain rates. Construction and building materials 2015, 93, 404-415.

(20) Debye, P.; M., B. A. Scattering by an inhomogeneous solid. Journal of Applied Physics 1949, 20, 518.

(21) Treloar, L. R. G. In The physics of rubber elasticity; Oxford University Press, N. Y., Ed.; 1975.

(22) Arruda, E. M.; Przybylo, P. A. An investigation into the three-dimensional stressbirefringence-strain relationship in elastomers. Polymer Engineering \& Science 1995, $35,395-402$.

(23) Mertz, F. Étude de la synthèse et de la caractérisation du Polyvinylbutyral. Influence des caractéristiques du polymère sur la structure des films. Répartition de l'Eau au sein des Films plastifiés. Ph.D. thesis, ENSCMu, 1992.

(24) Courtois, J.; Baroudi, I.; Nouvel, N.; Degrandi, E.; Pensec, S.; Ducouret, G.; Chanéac, C.; Bouteiller, L.; Creton, C. Supramolecular soft adhesive materials. Advanced Functional Materials 2010, 20, 1803-1811.

(25) Vechambre, C.; Callies, X.; Fonteneau, C.; Ducouret, G.; Pensec, S.; Bouteiller, L.; Creton, C.; Chenal, J.-M.; Chazeau, L. Microstructure and self-assembly of supramolecular polymers center-functionalized with strong stickers. Macromolecules 2015, 48, 82328239 .

(26) Stadler, R.; Freitas, L. d. L. Thermoplastic elastomers by hydrogen bonding. 1. Rheological properties of modified polybutadiene. Colloid and polymer science 1986, 264, $773-778$. 
(27) Botterhuis, N. E.; Van Beek, D.; van Gemert, G. M.; Bosman, A. W.; Sijbesma, R. P. Self-assembly and morphology of polydimethylsiloxane supramolecular thermoplastic elastomers. Journal of Polymer Science Part A: Polymer Chemistry 2008, 46, 38773885.

(28) Feldman, K. E.; Kade, M. J.; Meijer, E.; Hawker, C. J.; Kramer, E. J. Model transient networks from strongly hydrogen-bonded polymers. Macromolecules 2009, 42, 90729081.

(29) Leibler, L.; Rubinstein, M.; Colby, R. Dynamic of Reversible Networks. Macromolecules 1991, 4701-4707.

(30) Hoy, R. S.; Robbins, M. O. Strain hardening in polymer glasses: limitations of network models. Physical Review Letters 2007, 99, 117801.

(31) Chen, K.; Schweizer, K. S. Suppressed segmental relaxation as the origin of strain hardening in polymer glasses. Physical Review Letters 2009, 102, 038301.

(32) Janeschitz-Kriegl, H. Polymer melt rheology and flow birefringence; Springer Science \& Business Media, 1983; Vol. 6.

(33) Read, B. Dynamic birefringence of polymethylacrylate. Polymer 1964, 5, 1-18.

(34) Klock, D. Contribution à l'étude des feuilletés verre-polymère: synthèse et structure du poly(vinylbutyral) en relation avec ses propriétés mécaniques et adhésives. Ph.D. thesis, ENSCMu, 1989.

(35) Iwasaki, R.; Sato, C.; Latailladeand, J.; Viot, P. Experimental study on the interface fracture toughness of PVB (polyvinyl butyral)/glass at high strain rates. International Journal of Crashworthiness 2007, 12, 293-298.

(36) Bergstrom, J.; Boyce, M. Constitutive modeling of the large strain time-dependent behavior of elastomers. Journal of Mechanics and Physics of Solids 1998, 46, 931-954. 
(37) Fatt, M. S. H.; Ouyang, X. Three-dimensional constitutive equations for styrene butadiene rubber at high strain rates. Mechanics of Materials 2008, 40, 1-16.

(38) Demiray, H. A note on the elasticity of soft biological tissues. Journal of biomechanics $\mathbf{1 9 7 2 , ~ 5 , ~ 3 0 9 - 3 1 1 . ~}$

(39) Nakamura, Y.; Sakai, Y.; Adachi, M.; Fujii, S.; Sasaki, M.; Urahama, Y. Effects of compatibility of acrylic block copolymer and tackifier on phase structure and peel adhesion of their blend. Journal of Adhesion Science and Technology 2008, 22, 1313-1331.

(40) Haque, M. A.; Kurokawa, T.; Gong, J. P. Super tough double network hydrogels and their application as biomaterials. Polymer 2012, 53, 1805-1822.

(41) Lin, W.-C.; Fan, W.; Marcellan, A.; Hourdet, D.; Creton, C. Large strain and fracture properties of poly (dimethylacrylamide)/silica hybrid hydrogels. Macromolecules $\mathbf{2 0 1 0}$, 43, 2554-2563.

(42) Luo, F.; Sun, T. L.; Nakajima, T.; Kurokawa, T.; Zhao, Y.; Ihsan, A. B.; Guo, H. L.; Li, X. F.; Gong, J. P. Crack blunting and advancing behaviors of tough and self-healing polyampholyte hydrogel. Macromolecules 2014, 47, 6037-6046.

\section{For Table of Contents Use Only}

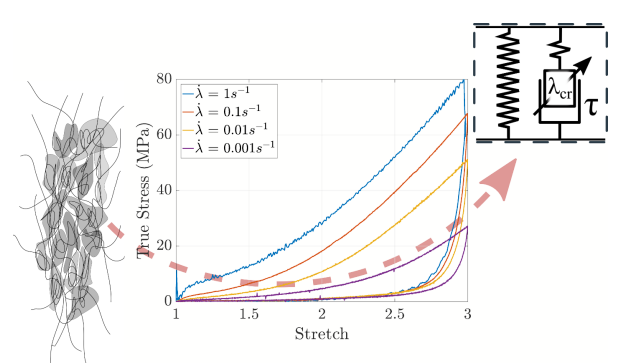

Supramolecular structure for large strain dissipation and outstanding impact resistance in Polyvinylbutyral, by Paul Elzière, Paul Fourton, Quentin Demassieux, Alexis Chennevière,

Cécile Dalle-Ferrier, Costantino Creton, Matteo Ciccotti and Etienne Barthel. 